\title{
LUM, presencias resignificantes del conflicto armado peruano ${ }^{1}$
}

\author{
Ana Claudia De Oliveira' \\ https://orcid.org/0000-0002-6528-8143 \\ Lilian Kanashiro" \\ https://orcid.org/0000-0003-0486-3105 \\ I - PUC São Paulo. \\ São Paulo (SP), Brasil. \\ II - Universidade de Lima. \\ Lima, Peru.
}

Resumen: El Lugar de la Memoria, de la Tolerancia y de la Inclusión Social (LUM) en Lima es parte de una política pública de la memoria enfocada en el conflicto armado interno peruano (1980 a 2000). Bajo una mirada sociosemiótica el presente trabajo tiene como objetivo analizar el LUM como espacio público y productor de afectos significantes. Se llevó a cabo una revisión documental y observación participante que revelan una disputa nominativa en su gestación política y una transformación afectiva en el trayecto de los visitantes.

Palabras claves: sociosemiótica; identidad; presencia; lugar de la memoria.

\footnotetext{
Abstract: LUM, Re-significant Presences of The Peruvian Internal Armed Conflict - The Place of Memory, Tolerance and Social Inclusion (LUM) in Lima is part of public memory policy focused on The Peruvian Internal Armed Conflict (19802000). Under a sociosemiotic gaze, the present work aims to analyze the LUM as a public space and significant affections producer. A document review and

1 Este trabajo es resultante del proyecto de investigación interinstitucional Práticas de vida e produção de sentido nas metrópoles latinoamericanas firmado entre a PUCSP: Programa de Pós-Graduação em Comunicação e Semiótica |CPS - Centro de Pesquisas Sociossemióticas, a Universidad de Lima e a PUCP en desarrollo en el período 2019-2021.
} 
a participant observation were carried out revealing a nominative dispute in its political elaboration and an affective transformation in visitors' journey.

Keywords: sociosemiotic; identity; presence; place of memory.

Resumo: LUM, presenças ressignificantes do conflito armado peruano - $O$ lugar da Memória, da Tolerância e da Inclusão Social (LUM) em Lima é parte de uma política pública da memória focada no conflito armado interno peruano (1980 a 2000). Sob uma abordagem sociossemiótica, o presente trabaIho tem como objetivo analisar o LUM como espaço público e como espaço produtor de afetos significantes. Realizou-se uma revisão de documentos e observação participante que mostram tanto a disputa em torno da nomeação da instituição durante a sua gestação política quanto a transformação afetiva que marca o trajeto dos visitantes.

Palavras-chave: sociossemiótica; identidade, presença, lugar da memória.

\section{Introducción}

El Lugar de la Memoria, de la Tolerancia y de la Inclusión Social (LUM), localizado en Lima, es el resultado de la implementación de una política pública de la memoria enfocada en el conflicto armado interno que ocurrió en el Perú entre 1980 a 2000. A partir de una perspectiva sociosemiótica el presente trabajo tiene como objetivo analizar el LUM como espacio público que, en su nominación, instala un destinatario localizado espacial y temporalmente en un pasado reciente, por medio del cual emerge una acción en el presente con miras hacia el futuro. Los tres universos semánticos del lugar (memoria, tolerancia e inclusión) están precedidos de artículos determinantes que configuran una sumatoria de tres semantismos enumerados en un modo particular de correlación y que nos conduce a la hipótesis de ser enunciados con la finalidad de promover un posicionamiento a partir de la axiología que pone en circulación, tanto para los peruanos como para los visitantes, habitantes del mundo, e incluso hasta pensado para llegar al mundo global actual. Con ese propósito de rearticulación de los sentidos ahí instalados nuestra pregunta de investigación es ¿cómo ese enunciado configura las acciones y prácticas del LUM?

Desde su creación el LUM forma parte del sistema de museos del Estado peruano, catalogado como lugar de la memoria bajo la jurisdicción del Ministerio de Cultura. Inaugurado el 2015, su gestión fue parte de un proceso de diálogo y de negociación que son propios de la formulación de políticas públicas en las cuales participaron diversos actores y grupos de interés (LEDGARD et al., 
2018). Un posicionamiento aparece explicitado como propio de la localidad que torna visible una apertura y que confiere al lugar una configuración memorialista. En ese sentido, tanto la tolerancia como la inclusión social aparecen como una revisión de los estados de ánimos y del alma antes que de un estado de las cosas.

\section{Nombrando la experiencia}

Un aspecto interesante cuando los seres humanos viven experiencias extremas de violencia y sus secuelas es la necesidad de las palabras para darle nombre $y$, en la búsqueda y encuentro de nominaciones, se tiene el acto de significar y resignificar las afectaciones fóricas (eufóricas o disfóricas) producido por lo vivido. La creación del LUM es una muestra de la necesidad de esa operación semiótica que carga en ella misma el vector teleológico de impulso de una nueva práctica social a partir de la resignificación (OLIVEIRA, 2017a, p.18-19).

En el año 1980 coinciden dos hechos importantes para la historia peruana. De un lado, se inicia un nuevo periodo democrático después de 12 años de dictadura militar y, de otro lado, se inicia el denominado conflicto armado interno o terrorismo con la quema de urnas electorales en un pequeño poblado de la región Ayacucho². La nominación usual y cotidiana durante ese periodo y que sobrevive hasta hoy, es la de terrorismo. La denominación conflicto armado interno es colocada en el Informe final de la Comisión de la verdad y reconciliación (CVR) encargada de examinar e investigar el periodo de violencia. Aún cuando todavía existe una controversia sobre la terminología empleada, la CVR emplea este término en concordancia con los Pactos de Ginebra. En la discusión local, muchas veces esta forma de nominación es entendida como un acto de sublimación del horror vivido durante aquellos años. En términos formales, el término conflicto armado interno, en el ámbito del derecho internacional, es para diferenciarse de la criminalidad ordinaria, función que también cumple el término terrorismo.

Para los ciudadanos comunes que poco o nada manejan el derecho internacional y la formalidad del lenguaje, la expresión recurrente es la mención época del terrorismo remitiendo, a través de esa expresión natural y espontánea, 
la estesia de la historia. Sobre este lexema, emergen los valores sensibles vinculados a la experiencia vivida y animada por los recuerdos: /miedo/ y / muerte/. Tampoco está fuera de la formalidad del lenguaje el empleo del término "terrorismo" a la violencia vivida, las normas señalan que se aplica a actos concretos como secuestro, ataques a la población civil, atentados, etc. Mas el empleo social del término difiere en mucho de la normativa del lenguaje jurídico, donde se nombraba como "terrorismo" a la época de la violencia proveniente principalmente de los movimientos subversivos peruanos: Sendero Luminoso y Movimiento Revolucionario Túpac Amaru (MRTA).

En el ámbito de una intensa crisis política que llevó a la destitución del presidente Fujimori, el entonces presidente Valentín Paniagua conformó la Comisión de la verdad con la finalidad de investigar los sucesos durante el periodo de violencia (DECRETO SUPREMO Nº65-2001-PCM). Una norma posterior (DECRETO SUPREMO N 101-2001-PCM) altera el nombre de la recién creada comisión como Comisión de la verdad y reconciliación (CVR). El añadido a la nominación previa del término reconciliación nos plantea un estado del alma más que un estado de las cosas. ¿Por qué era necesario sumar reconciliación al término verdad?

La CVR trabajaba en medio de un ambiente muy polarizado. La presión de la sociedad civil por medio de los organismos de derechos humanos, las asociaciones de los familiares de los desaparecidos y las víctimas, durante este periodo, era un clamor persistente. Incluso aunque el país hubiera comenzado su proceso de pacificación en el año 1992 con la captura del líder de Sendero Luminoso, Abimael Guzmán, existía una serie de demandas insatisfechas para esclarecer los hechos que envolvieron a los agentes del Estado y las responsabilidades penales y civiles respectivas. La creación de la CVR tenía como finalidad buscar respuestas a estos pedidos. Por otro lado, un sector político y ciudadano personificaba en el presidente Fujimori el papel de pacificador del país y consideraba que la CVR tenía una tendencia ideológica que no reconocía el trabajo de las Fuerzas Armadas y Policiales que también habían sido víctimas de la subversión. Ante esta situación de polarización se incluye la expresión reconciliación.

Este cambio de nominación configura un Destinador (Estado) que otorga un nuevo objeto de valor al destinatario (Comisión de la verdad), que debe entonces incluir en su misión, además de la verdad, también la reconciliación. Teniendo en vista que esto ocurre en un contexto de alta polarización, 
se tiene una recalificación del modo de hacer de la comisión. No solamente su recorrido debe ser el de encontrar la verdad, mas, haciendo eso, debe hacerlo también promoviendo la reconciliación.

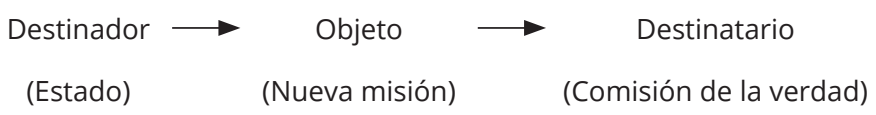

Podemos señalar que la misión de buscar la verdad se encuentra en las modalidades del /hacer saber/ de orden cognitivo, el Estado agrega a la comisión una modalidad de orden diferente /hacer unir/. Reconciliar es unir lo que está polarizado, contribuir a mitigar el conflicto que los separa. Además, es la presunción de que lo que está en conflicto estuvo antes en armonía, elemento discutible a partir de una revisión histórica del Perú. Con la mudanza de nominación, la CVR recibía encargos adicionales en el plano semántico. Es así como, después de dos años de trabajo intenso que implicó la realización de audiencias públicas y la recopilación de un poco menos de 17,000 testimonios, la CVR entregó su informe final el 2003. El informe final de la CVR y el antecedente que dio origen al LUM, y como mencionáramos más adelante, fue parte de las disputas entre el museo de la CVR y un lugar de la memoria.

\section{La génesis del LUM}

Como parte de este trabajo, se llevó a cabo una recopilación documental de las normas que crearon el Lugar de la Memoria, de la Tolerancia y de la Inclusión Social (LUM). Una línea del tiempo reconstruida evidencia un proceso de casi diez años que organizamos en dos etapas con dos destinadores diferentes: la gestión impulsada por la Presidencia del Consejo de Ministros (PCM) y la gestión impulsada por el Ministerio de Cultura. Dos destinadores que en tiempos diferentes organizan una reescritura de la narrativa histórica vivida que, en el conjunto de sus objetivos, define un modo de concebir el LUM.

\section{Del Museo de la Memoria al Lugar de la Memoria (2009-2015)}

Los orígenes del LUM se remontan al trabajo de la CVR cuyo informe final estuvo compuesto por nueve tomos que describe en detalle 20 años de terror que vivieron los peruanos, cumpliendo con su misión de /hacer saber/. El informe recomendó la creación de una Comisión Nacional de la 
Reconciliación que incluyera un programa denominado “b) programa de memoria histórica [...]" (COMISIÓN DE LA VERDAD Y RECONCILIACIÓN, 2003, p. 297). Con ella se señalaba que la misión encomendada de reconciliación /hacer unir/ estaba pendiente. En esa recomendación podemos observar que una medida necesaria para dar continuidad al proceso iniciado por la CVR estaba en estricta relación con la memoria de los acontecimientos, esto es, como una revisión del estado de las cosas. No obstante, esta recomendación no prosperó.

El 31 de marzo de 2009 se crea la comisión de alto nivel "Museo de la Memoria" (RESOLUCIÓN SUPREMA Nº59-2009-PCM) que, con el compromiso de la cooperación alemana, se disponía a dar inicio a uno de los proyectos culturales contemporáneos más polémico del país. La comisión fue presidida por Mario Vargas Llosa, figura internacional proveniente de las letras y de la cultura.

Nuevamente, las palabras son el centro de diputas, la Resolución Suprema Nº98-2010-PCM publicada el 14 de abril de 2010 establece el cambio de nominación de Museo de la Memoria por Lugar de la Memoria. La resolución señala que el término museo remite a la idea de recordación del pasado, en tanto el término lugar era el más apropiado por ser el término más empleado en otros países al relacionar la expresión con el significado e intención de evitar la repetición futura de dichos acontecimientos. Por un lado, observamos un semisimbolismo temporal, museo : pasado :: lugar : futuro; y por otro lado un semisimbolismo espacial, museo : local :: lugar : global.

El cambio de nombre plantea la resignificación del LUM en tanto integración a un círculo internacional asimilando por adecuación la tendencia global exógena. Si bien la violencia nos coloca delante de la comunidad internacional como un Otro aberrante y vergonzoso, el LUM se convierte en el mecanismo que transforma nuestras vergüenzas pasadas en instrumentos de internacionalización. Por oposición, se manifiesta la implicancia de mantener la palabra museo como signo de auto segregación o aislamiento en el dolor ${ }^{3}$. Así, distanciado de si mismo, es el propio gobierno en cuanto entidad representante del país que opta por una reconstrucción de si mismo. Como Landowski (2002) señala: 


\begin{abstract}
a alteridade do outro atribuindo um conteúdo específico à diferença que me separa dele. Assim, quer a encaremos no plano da vivência individual ou [...] da consciência coletiva, a emergência do sentimento de 'identidade' parece passar necessariamente pela intermediação de uma 'alteridade' a ser construída (p. 5).
\end{abstract}

La sede del LUM se ubica en la Costa Verde, zona costera de Lima, capital del Perú. La sede es concebida para irrumpir en el acantilado e irse en sus angulaciones hacia el mundo exterior por el Pacífico. Con esa dinámica del eidético, en un tipo de color y materialidad homogeneizadora de vectores solidos de fuerzas, el LUM se presenta como la construcción de una presencia que se abre al mundo para ser vivida, una presencia con visibilidad para realizar su propósito de dar forma a una nueva identidad al Perú y, transitivamente a la población que vivió el terrorismo.

La iniciativa no es enteramente nueva. Sobre eso, podemos señalar la existencia de una significación de lugares dedicados a la memoria. Por un lado, un sistema paradigmático global que agrupa los lugares de la memoria en todo el mundo, además también un sistema paradigmático local. A nivel local, el Perú cuenta con centenas de expresiones dedicadas a recordar los hechos de violencia del periodo estudiado y rendir tributo a sus víctimas. Cada una con formas de expresión diferentes como monumentos, placas conmemorativas, plazas de la memoria. Muchas de ellas basadas en el discurso occidental que no remite a las prácticas propias de conmemoración de las comunidades afectadas por la violencia (LEDGAR et al., 2018). También muchas de esas formas de rememoración son financiadas por la cooperación internacional, o son promovidas por las ONGs en alianza con la sociedad civil. Con esas características el LUM es el lugar nacional de la memoria promovido por el Estado.

En el inicio del gobierno de Ollanta Humala Tasso, este promovió una resolución que establece otra mudanza de nominación de "Lugar de la Memoria” por el nombre que actualmente exhibe "Lugar de la Memoria, de la Tolerancia y de la Inclusión Social". Una resolución precisa que esa nueva denominación marca con mayor claridad el mandato de la Comisión de Alto Nivel, de mantener un enfoque plural enfatizando "la prioridad nacional de la tolerancia y de la inclusión social como valores fundamentales y tareas pendientes [...]" (RESOLUCIÓN SUPREMA N 405-2011-PCM, 2001, p. 455904). De la misma manera que sucedió al respecto de la CVR, el Lugar de la Memoria es destinatario de nuevas misiones. 


$$
\begin{aligned}
& \text { Destinador } \longrightarrow \text { Objeto } \longrightarrow \quad \text { Destinatario } \\
& \text { (Estado) (Nueva misión) (Lugar de la memoria) }
\end{aligned}
$$

Inicialmente la misión del LUM fue presentar la memoria sobre la modalidad del /hacer recordar/, nos encontramos ahora delante de una mudanza de gestión política con la suma de misiones extras como promover la tolerancia y la inclusión social sobre la modalidad de un /hacer re-unir/. Aunque son objetivos nobles para el bienestar del país, observamos de manera reiterada la praxis enunciativa del Estado destinador agregando objetivos. Notamos que entre una experiencia y otra hay diferencias significativas, en tanto la CVR le era encomendado el /hacer reconciliar/, al LUM se le encomienda el /hacer tolerar e incluir/. Esa diferencia de haceres nos conduce a reflexionar sobre dos regímenes de interacción que el Estado encarga, en momentos diferentes, al destinatario LUM. En el primer caso, el /hacer reconciliar/ está en el régimen de asimilación, unir lo que está separado, en cuanto que en el /hacer tolerar e incluir/ podemos notar un tránsito entre un régimen de segregación (soportar al Otro en su diferencia) sobre la expresión tolerancia y un régimen de asimilación (incluir al Otro con los mismo derechos, pero sobre las reglas universales del nosotros dominante) sobre la expresión inclusión social, esos regímenes que promueven interacciones distintas, así como promueven visibilidades identitarias distintivas y que tomamos de Landowski (2002) en su tratamiento de las Presencia del Otro.

Hasta el momento, los archivos documentales muestran la creación del LUM como esa iniciativa proveniente de la Presidencia del Consejo de Ministros, el más alto órgano ejecutor de las políticas públicas. Es así como la creación del LUM toma parte de lo que conoce como política pública de la memoria que se inauguró el 17 de diciembre de 2015 durante el gobierno de Ollanta Humala.

\section{Del Lugar de la Memoria a la memoria del mundo (2015-2018)}

Una vez inaugurado el LUM, fueron necesarios tres años de gestiones y negociaciones para hacerlo operativo ${ }^{4}$, en este proceso se incluye el diseño del guion museográfico y la propuesta de contenido. El 3 de agosto de 2018, el LUM es integrado al Sistema Nacional de Museos del Estado Peruano y

4 El Ministerio de Cultura crea un área funcional de carácter temporal (Resolución Ministerial Nº 455-2015-MC y Resolución Ministerial N 387-2016-MC), nombra a la comisión encargada de formular los lineamientos (Resolución Ministerial No 452-2017-MC) y aprueba los mismos el 2018. (Resolución Ministerial N²47-2018-MC). 
clasificado como uno de los lugares de la memoria. Esa clasificación es atribuida a los "espacios orientados para construir una sociedad basada en la cultura de paz y solidaridad" (RESOLUCIÓN MINISTERIAL Nº 304-2018-MC, 2018 , p. 17). La norma señala que la memoria es entendida como un proceso en continua construcción, basado en una constante crítica y aprendizaje. El acervo documento de la CVR fue incorporado al Registro Nacional del Comité de Memorias del Mundo para América Latina de la UNESCO, lo que supone una sanción positiva social-global y un posicionamiento del cultivo de la memoria en detrimento de la amnesia, que opera como apagones enteros de la historia de vida tanto del país como de la población.

Con esta última norma encontramos nuevamente la recurrencia semisimbólica espacio temporal en el cual museo : pasado :: lugar : futuro e museo : local :: lugar : global. Al integrarlo a la red de muesos nacionales, el Estado reconfigura la significación de local como nacional. $Y$ al visibilizar que es parte del acervo de la UNESCO concluye que el LUM y todo lo que significa se encuentra plenamente integrado a lo global. El Estado en su oficio de gestionar las políticas públicas de la memoria cumple el papel de asimilador global que integra al LUM en una red nacional y a un registro global. La sanción positiva de la UNESCO da visibilidad a una acción que el mundo global ha asumido como ejemplar pues lo vivido en el Perú no se restringe exclusivamente solo a ese país, y esa acción lo torna ejemplar y desencadena un /hacer propagandístico/ (LANDOWSKI, 2014, p. 20-21) operando una propagación ideológica sobre la posibilidad de producir cambios en la historia del mundo como el cambio de las prácticas sociales.

\section{EI LUM y su relación con la ciudad}

Durante la creación del LUM, la gestión del guion museográfico fue el momento que evidenció los diferentes intereses en disputa. La gestión de este envolvía tanto el diseño del proyecto arquitectónico del edificio como la elaboración del contenido que la edificación abrigaría.

La elaboración de los contenidos supuso la negociación de varias narrativas de la memoria en combate directo a una amnesia de la historia vivida. Existían tres narrativas que se disputaban su reconocimiento: a) memoria salvadora de carácter hegemónico y triunfalista en la cual la violencia fue superada, b) la memoria subversiva no hegemónica que proponía una narrativa heroica y, c) la memoria de resistencia proveniente de la CVR y asociaciones de victimas en la cual la violencia no era un episodio clausurado. Al ser el LUM un lugar de memoria nacional se trataba de representar una 
memoria basada en una "narrativa y sentido despersonalizado" (LEDGARD et al., 2018, p. 14) que integraba las diversas voces que fueron parte constitutiva de ese periodo.

De la misma manera que la elaboración de una guía de contenidos tiene un proceso, lo mismo sucede con la construcción y diseño del edificio que actualmente acoge al LUM. La Municipalidad de Miraflores otorgó una cesión de 8000 metros cuadrados para la edificación del LUM y para el diseño de arquitectónico se convocó a un concurso público en la que se presentaron 350 estudios otorgándose la buena pro al estudio Barclay \& Crousse. La implementación y conclusión de la edificación enfrentó numerosas dificultades administrativas y financieras, que incluyó también la confrontación con un proyecto inmobiliario y comercial que afectaba las zonas de acceso peatonal del futuro LUM, así como las dificultades y costos propios de una edificación incrustada en el acantilado de la Costa Verde Lima.

La edificación resultante está conformada por un sótano y tres pisos conectados por dos rampas. En el sótano se localiza el auditorio que es destinado a actividades culturales del LUM. Los tres pisos de la edificación y sus dos rampas están destinados a la muestra permanente. Luego de ser aprobada la tercera y definitiva guía de contenidos, el responsable museográfico fue el arquitecto Juan Carlos Burga cuya función era asegurar que "los contenidos curatoriales dialogasen con la realidad del predio" (LEDGARD et al., 2018, p. 46).

Con una clara orientación modernista y minimalista, los exteriores del LUM está conformado por bloques de concreto armado lo que crea una analogía con las cualidades geológicas del lugar. La morfología de la edificación se incrusta en el acantilado de la Costa Verde de Lima, conformada por una serie de formaciones rocosas desgastadas por la erosión de la naturaleza, en semejanza al uso del espacio por la temporalidad, van a construir el efecto de sentido de que la edificación del LUM es parte de una serie de formaciones rocosas. El impacto de esta estrategia por propagación ideológica (LANDOWSKI, 2014) es explícita, lo que nos lleva a concluir que la edificación produce sinestesia que, al ser sentida desencadena afectaciones en los estados del alma y del ánimo (OLIVEIRA, 2017b, p. 167-168), ellas van conduciendo a los visitantes a la adhesión del propósito del LUM. 


\section{El interior del LUM}

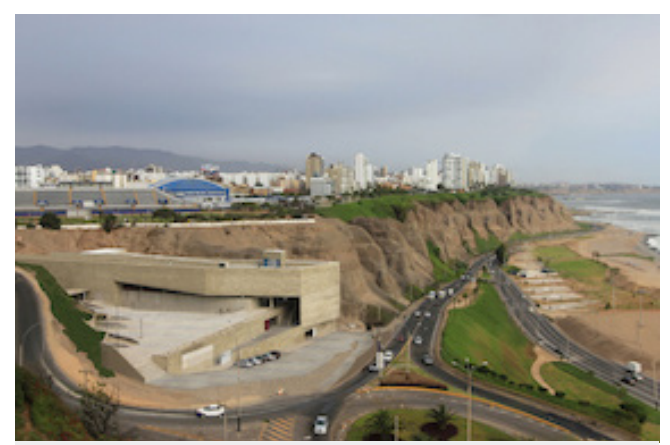

Fig. 1. Localización del LUM en la ciudad de Lima. Nota: CIGARINI Y SAAVEDRA (2015).

Como se señaló anteriormente, el edificio está formado por un sótano (área de eventos) y tres niveles (muestra permanente). Los interiores están conformados por espacios amplios e iluminados por grandes ventanas verticales. Las divisiones de las salas están dadas por el mobiliario que contiene el contenido de la muestra permanente.

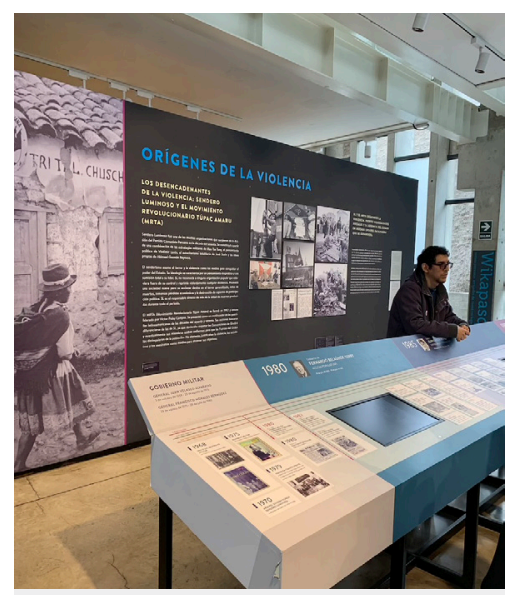

Fig. 2. Sala Perú 1980-2000.

Dominan en el primer nivel, paneles con información escrita y gráfica, y eventualmente, informaciones en pantallas que invitan al visitante a escuchar de manera 
privada mediante audífonos las escenas que observa. Los grandes panales ocultan el edificio y tienen como función conducir el trayecto del visitante.

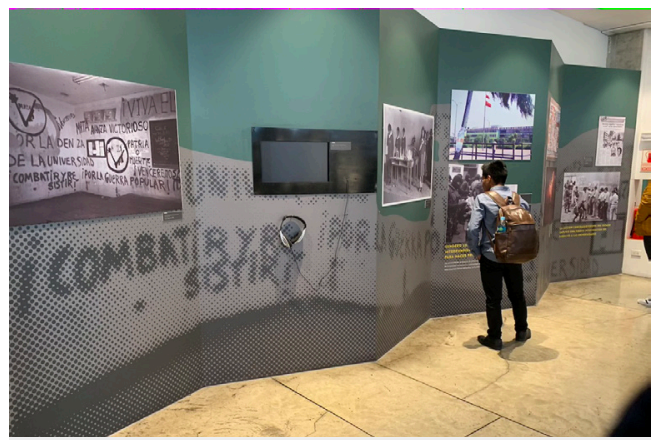

Fig. 3. Sala La violencia y el ámbito educativo.

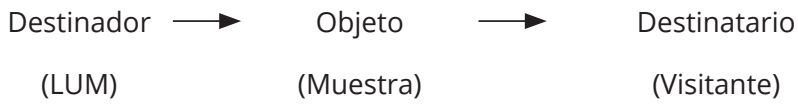

En la organización del panel (figura 3), el verde pálido en la parte superior representa la pizarra de las aulas y contrasta con el mundo inferior gris de la urbe limeña que en palabras-imágenes muestran las proclamaciones de las calles. Cada interacción con la imagen de la fotografía, con el video pasado en la televisión, con las palabras-imágenes de ayer y hoy; sitúan a los visitantes en dos mundos reunidos en la pared. La disposición es angular y, en cada plano, los ángulos atraen y alejan al destinatario como si nos capturase una implosión y nos llevasen al mundo de las proyecciones para el exterior. La interacción es de observación y genera una contemplación de las ocurrencias para tomar conocimiento y construir un saber.

En el extremo del primer piso nos encontramos con la sala 5 titulada Una persona, todas las personas. A diferencia de las salas anteriores, las características del edificio son más visibles y el espacio se muestra más abierto. En esa sala se colocaron una serie de pantallas en representación de los testimonios de los y las ciudadanas afectadas por la violencia.

El panel está en el sentido vertical, combinan la interacción contemplativa con la privada por medio de la escucha individual que se realiza por los audífonos (figura 4). Las indicaciones introductorias en la pared de la sala hacen saber que 
cada panel es interactivo y se accionan por medio del tacto, la mayoría de los visitantes tienen acceso a esa instrucción al ver la experiencia de otros visitantes.

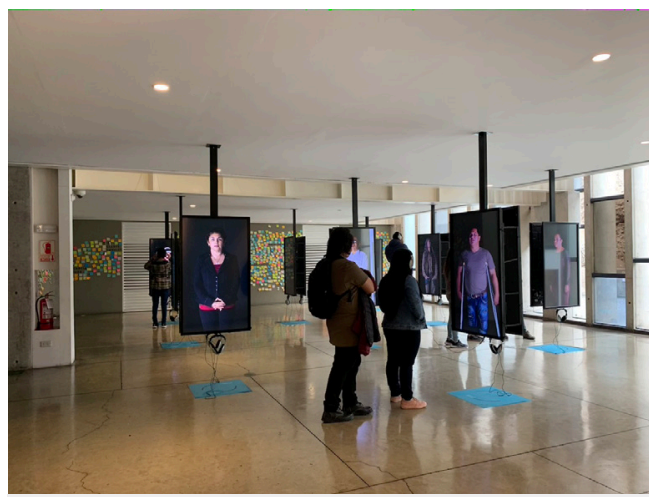

Fig. 4. Sala Una persona, todas las personas.

En algunos casos, los testimonios están en la lengua originaria del testimonio y la traducción es hecha por leyendas verbales escritas, lo que nos pone delante de un testimonio subtitulado que leemos y oímos al movernos lentamente en el espacio (figura 5). La lectura de la leyenda es un modo de tomar conocimiento de ese testimonio que es dado en una de las lenguas vivas habladas en el Perú.

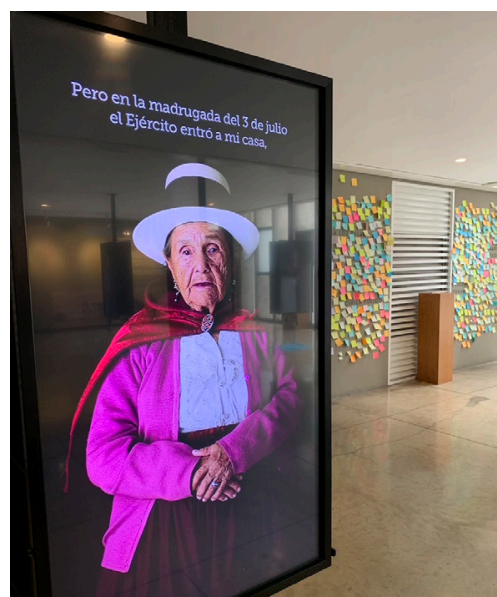

Fig. 5. Testimonio de Angélica Mendoza de Ascarza. 
Las paredes que rodean el recinto son mostradas en colores grises y ellas reciben los nombres de las personas cuyos testimonios están colocados en las pantallas. Estas paredes están cubiertas con notas escritas por los visitantes que son unidas verticalmente, lado a lado, unas con otras, por los papeles autoadhesivos tan presentes en la cotidianidad. Son en ellos que se puede leer los diversos mensajes dirigidos a aquellos que acabaron de oír y ver, narrando sus testimonios. Figurando en los diversos colores de los cuadriláteros que por si sólo atraen la atención de las personas, esos diálogos con los testimonios se procesan a continuación en los actos de lectura de los otros visitantes. De nuevo, la interacción es silenciosa, mas plena de interlocuciones que van llegando al público y sensibilizándolo también a dar su testimonio. La red conversacional así tejida hace la escucha de los testimonios transformarse en nuevos testimonios (figura 6).

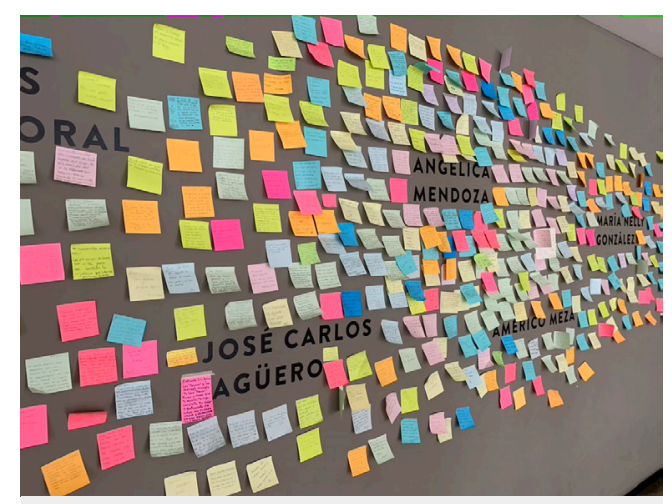

Fig. 6. Mensajes de los visitantes.

La interacción deja de ser pasiva y unidireccional para ser activa, aunque se mantiene la unidireccionalidad. Algunos nombres en mayúscula aparecen acá y allá en la larga pared reforzando el sentido de registro de las voces de los visitantes que no solo circulan por el lugar, mas dan su testimonio escrito. Ese acto performativo hace ver una interacción interlocucional transitiva, interacción doble en el asumir que cada uno tiene un turno para hablar. El segundo piso repite el mismo patrón de dividir las salas con los paneles de la muestra. En el se ofrece más espacio a la exhibición de objetos ligados a la muestra (figura 7). 


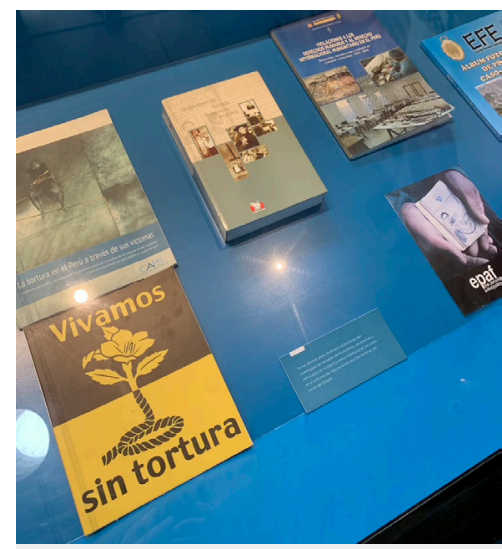

Fig. 7. Sala Objetos de memoria.

Los techos también son blanco de intervenciones, bajo la forma de una serie de tejidos que aparecen en círculos uno al lado del otro. Así, dispuestos en yuxtaposición y paralelismo en toda la verticalidad de lo alto, ellos van a colorear los techos y nos hacen mirar ese cielo como si estuviésemos creando otro cielo para Lima (figura 8), en el cual inscribimos ese hacer cultural que vive el país e ilumina la vida peruana. Así, ese cielo-techo textil, de manufactura táctil por los movimientos de las manos, se muestra iluminando el gris de la capital. Se trata de una reconstrucción hilvanada punto a punto, que teje, que borda, que reescribe en una mezcla de varios haceres a los propios peruanos manifestándose a través de una de las artesanías más significantes de su cultura. Así, se tiene otros tantos modos de presencia que a partir de tantas otras voces dan sus testimonios en el LUM, haciendo ver el brotar de otra manifestación frente a los hechos ahí encontrados que conquistan solidaridad.

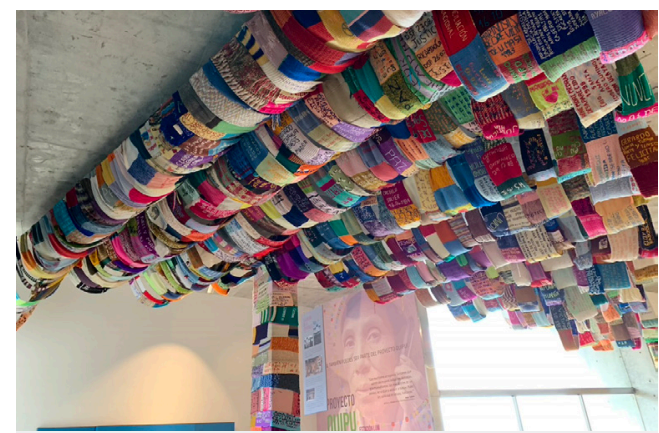

Fig. 8. Sala Iniciativas de memoria, verdad y justicia. 
En el tercer piso está la salida que es configurada predominantemente por un espacio escalonado que conduce al visitante en dirección al mirador, un espacio vacío que ofrece un panorama abierto (figura 9). De ahí, el observador, paso a paso se desvela el Océano Pacífico, la ciudad, el mundo, es como si el visitante ganase su acceso a su lugar de habla, de testimonio. A partir de cada grada, los pasos recorridos lentamente en el interior del LUM transportan al visitante para llegar ahí como sujeto competente por las acciones de la visita para llevar su testimonio a todos los rincones.

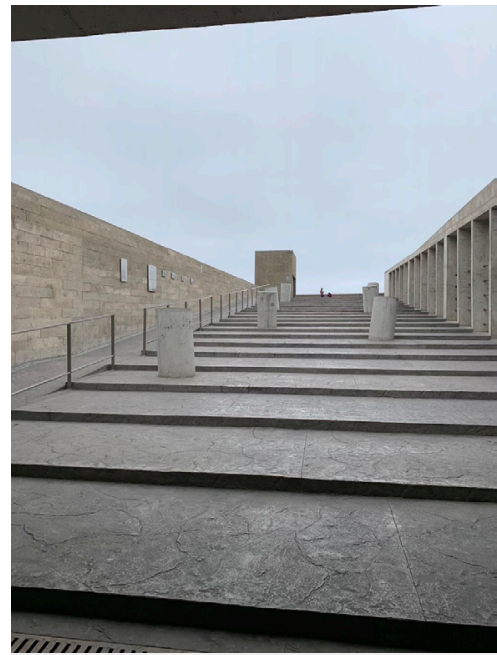

Fig. 9. Salida del LUM.

\section{¿Final de la visita o solo el comienzo?}

Afectado, el visitante en su transformación de estado vivida en el LUM apenas comienza a posicionarse en el Perú de hoy. Como Lugar de la Memoria, de la Tolerancia y de la Inclusión Social, el tiene mucho que testimoniar local y globalmente. Vamos a esperar oír sus testimonios delante de la historia reciente que se reconfigura en otras más en la vida social. La salida difícil hacia las calles de Lima hace ver que aún hay roles por vivir para todos en este desafío de (re) construcción del país.

Ana Claudia de Oliveira é professora titular da Pontifícia Universidade Católica de São Paulo, atuando na PósGraduação em Comunicação e Semiótica. É líder do 
Centro de Pesquisas Sociossemióticas - CPS. Suas pesquisas concentram-se no âmbito da estética e estesia nas semióticas das práticas de vida, semiótica da cidade, semiótica das mídias, semiótica da arte.

anaclaudiamei@hotmail.com

Lilian Kanashiro é professora titular da Universidade de Lima, atuando na Facultad de Comunicación e no Instituto de Investigación Científica (IDIC). É líder do Grupo de Investigación Semiótica - Universidad de Lima e editora do periódico Contratexto. Suas pesquisas concentram-se no âmbito da semiótica, das práticas de vida e do jornalismo contemporâneo.

liliankanashiro@hotmail.com

Contribuição de cada co-autor: ambas trabalharam na: 1) investigação de campo; 2) metodologia e análise formal do corpus; 3) escrita, revisão e edição. Ana Claudia de Oliveira: fundamentação teórica e conceituação. Lilian Kanashiro: curadoria de dados; construção de figuras e tabelas.

\section{Referencias}

CIGARINI, T., Y SAAVEDRA, M. Un lugar para no olvidar. HABITAR. 2015. Disponible en: <https://bit.ly/3aVZ4GY>. Consultado el: 10 Nov. 2019.

COMISIÓN DE LA VERDAD Y RECONCILIACIÓN (Perú). Informe final. Lima, CVR, 2003. Disponible en: <https://bit.ly/3b8CJWJ>. Consultado el: 10 Nov. 2019.

DECRETO SUPREMO No 065-2001-PCM [Presidencia del Consejo de Ministros]. Crean Comisión de la Verdad. Lima: Editora Perú, 2001. Disponible en: <https://bit.ly/3jf2aje>. Consultado el: 10 Nov. 2019.

DECRETO SUPREMO No 101-2001-PCM [Presidencia del Consejo de Ministros]. Modifican la denominación de la Comisión de la verdad por la de la Comisión de la Verdad y Reconciliación. Lima: Editora Perú, 2001. Disponible en: <https://bit.ly/34ts6N7>. Consultado el: 10 Nov. 2019.

LANDOWSKI, E. Interações arriscadas. São Paulo: Estação das Letras e Cores, 2014.

Presenças do outro. Ensaios de sociossemiótica II. São Paulo: Editora Perspectiva, 2002. 
LEDGARD, D., HIBBETT, A. Y DE LAJARA; B. Retos y estrategias para una política de memoria: el proyecto Lugar de la Memoria, la Tolerancia y la Inclusión Social. Cuadernos de Investigación, № 7, 3-72. Lima: Escuela de Gobierno y Políticas Públicas de la Pontificia Universidad Católica del Perú. 2018. Disponible en: <https://bit.ly/2QDliUO>. Consultado el: 10 Nov. 2019.

OLIVEIRA, A. C. Uma São Paulo pelas práticas de vida. Do estudo semiótico dos discursos acabados aos das situações e das experiências vividas. En: OLIVEIRA, A. C. (Org.). São Paulo e Roma: Prática de vida e sentido. São Paulo: CPS y Estação das Letras e Cores, 2017a, p.13-32

Prefácio. In GREIMAS, Algirdas J. Da imperfeição. Trad. Ana Claudia de Oliveira. São Paulo: CPS y Estação das Letras e Cores, 2017b, pp. 165-168.

RESOLUCIÓN SUPREMA Nº 059-2009-PCM [Presidencia del Consejo de Ministros]. Crean la Comisión de Alto Nivel para la Gestión e Implementación del Proyecto “Museo de la Memoria". Lima: Editora Perú, 2009. Disponible en: <https://bit.ly/3lvB1DK>. Consultado el: 10 Nov. 2019.

RESOLUCIÓN SUPREMA Nº 098-2010-PCM [Presidencia del Consejo de Ministros]. Modifican denominación de "Museo de la Memoria" a que se refiere la R.S. $\mathbf{N}^{\circ} 059$ 2009-PCM por "Lugar de la Memoria" e incorporan miembros a la Comisión de Alto Nivel. Lima: Editora Perú, 2010. Disponible en: <https://bit.ly/3ltLKhP>. Consultado el: 10 Nov. 2019.

RESOLUCIÓN SUPREMA Nº 405-2011-PCM [Presidencia del Consejo de Ministros]. Cambian denominación y nombran miembros de la Comisión de Alto Nivel para organizar y poner en marcha el Lugar del Memoria, la Tolerancia y la Inclusión Social. Lima: Editora Perú, 2011. Disponible en: <https://bit.ly/3hJ5Hiv>. Consultado el: 10 Nov. 2019.

RESOLUCIÓN MINISTERIAL N 455-2015-MC [Ministerio de Cultura]. Confórmese el Área Funcional “Lugar de la Memoria, la Tolerancia y la Inclusión Social” del Ministerio de Cultura. Lima: Editora Perú, 2015. Disponible en: <https://bit.ly/3ji1we1>. Consultado el: 10 Nov. 2019.

RESOLUCIÓN MINISTERIAL N 387-2016-MC. [Ministerio de Cultura]. Disponer que el Área Funcional "Lugar de la Memoria, la Tolerancia y la Inclusión Social" conformada por Resolución Ministerial N 455-2015-MC, dependa de la Secretaría General. Lima: Editora Perú, 2016. Disponible en: <https://bit.ly/3lpvtuD>. Consultado el: 10 Nov. 2019.

RESOLUCIÓN MINISTERIAL N 452-2017-MC. [Ministerio de Cultura]. Crean Comisión Sectorial encargada de proponer lineamientos que servirán de guía para el desempeño del Área Funcional "Lugar de la Memoria, la Tolerancia y la Inclusión Social". Lima: Editora Perú, 2017. Disponible en: <https://bit.ly/32QVXN9>. Consultado el: 10 Nov. 2019.

RESOLUCIÓN MINISTERIAL N²47-2018-MC. [Ministerio de Cultura]. Aprueban los Lineamientos para el "Lugar de la Memoria, la Tolerancia y la Inclusión Social”. Lima: 
Editora Perú, 2018. Disponible en: <https://bit.ly/3gEWoiq>. Consultado el: 10 Nov. 2019.

RESOLUCIÓN MINISTERIAL N³04-2018-MC [Ministerio de Cultura]. Incorporan al Lugar de la Memoria, la Tolerancia y la Inclusión Social - LUM, al Sistema Nacional de Museos del Estado. Lima: Editora Perú, 2018. Disponible en: <https://bit.ly/3b9H5gr>. Consultado el: 10 Nov. 2019.

Artigo recebido em 10/10/2020 e aprovado em 30/11/2020. 